\title{
Colorimetric Determination of Sulfide in Microsamples
}

\author{
Shogo Sugahara, ${ }^{* 1}$ Mai Suzuki, ${ }^{* 1}$ Hiroshi Kamiya, ${ }^{* 2}$ Masumi Yamamuro, ${ }^{* 3}$ Hitoshi Semura, ${ }^{* 4}$ \\ Yukiko Senga, ${ }^{* 5}$ Michiko Egawa, ${ }^{* 1}$ and Yasushi SEIKE*1 \\ *1 Graduate School of Science and Engineering, Shimane University, 1060 Nishikawatsu, Matsue, \\ Shimane 690-8504, Japan \\ *2 Shimane Prefectural Institute of Public Health and Environmental Science, 582-1 Nishihamasada, Matsue, \\ Shimane 690-0122, Japan \\ *3 Institute of Geology and Geoinformation, Geological Survey of Japan (GSJ), AIST, Central 7, 1-1-1 Higashi, \\ Tsukuba, Ibaraki 305-8567, Japan \\ *4 Inland Water Fisheries and Coastal Fisheries Division, Shimane Prefectural Fisheries Technology Center, \\ 1659-1 Okinoshima, Sono-cho, Izumo, Shimane 691-0076, Japan \\ *5 Faculty of Science, Toho University, 2-2-1 Miyama, Funabashi, Chiba 274-8510, Japan
}

\begin{abstract}
A method for determination of hydrogen sulfide in microsamples $(200 \mu \mathrm{L})$ was developed by modifying the methylene blue method. Samples were collected using a micropipette and were combined with sulfide coloring reagent and $5 \mathrm{~mL}$ of $0.1 \mathrm{M} \mathrm{HCl}$ in test tubes. Absorbance of the solution was measured spectrophotometrically at $667 \mathrm{~nm}$. This modified method did not require any special labware or technique, and can be used in a variety of research fields.
\end{abstract}

Keywords Hydrogen sulfide, methylene blue method, microsamples

(Received February 16, 2016; Accepted June 24, 2016; Published October 10, 2016)

\section{Introduction}

The presence of hydrogen sulfide indicates a high level of toxicity in a variety of organisms. ${ }^{1-4}$ Hydrogen sulfide is produced in environmental water by sulfate-reducing bacteria as a result of anoxic reactions. Accordingly, hydrogen sulfide is a useful indicator of anaerobic states.

A typical method for the determination of hydrogen sulfide is the methylene blue method. ${ }^{5}$ In this method, a sulfide coloring reagent (comprising iron(III) chloride $\left(\mathrm{FeCl}_{3} \cdot 6 \mathrm{H}_{2} \mathrm{O}\right)$ and $N, N$-diethyl- $p$-phenylenediamine sulfate dissolved in $6 \mathrm{M} \mathrm{HCl}$ solution) is injected into the sample. After $15 \mathrm{~min}$, but within $2 \mathrm{~h}$, the absorbance is measured spectrophotometrically at $667 \mathrm{~nm}$. By changing the amounts of iron(III) chloride and $N, N$-diethyl- $p$-phenylenediamine sulfate, hydrogen sulfide contents can be determined across low $\left(0-2000 \mu \mathrm{gS} \mathrm{L}^{-1}\right)$ to high $\left(0-50 \mathrm{mgS} \mathrm{L}^{-1}\right)$ concentration ranges. ${ }^{6}$ Typically, glass syringes are used in this method. ${ }^{6-9}$ Samples for hydrogen sulfide determination are drawn directly into the glass syringes, without leaving any headspace, through an in-situ sampler into which zinc acetate solution is injected, and then sealed with a rubber cap. In the laboratory, $6 \mathrm{M} \mathrm{HCl}$ and sulfide coloring reagent are injected into the glass syringe. Glass syringes are suitable tools for determination of hydrogen sulfide because they have variable volumes, and the sample does not come into contact with air between sampling and measurement. However, for microliter-scale samples, this operation is difficult to achieve

† To whom correspondence should be addressed.

E-mail: suga@ riko.shimane-u.ac.jp using a glass syringe. As no other suitable labware was available, we were forced to operate in an open system.

In spectrophotometric methods, optimal cell sizes are chosen according to the adsorption wavelength of the measured substance; and the solution volume required for measurement is prescribed by the capacity of the cell used. When using 10 and $50-\mathrm{mm}$ cells, the solution volumes required for measurement, including rinsing the cell with water, are 10 and $30 \mathrm{~mL}$, respectively. Therefore, in cases where there is insufficient sample, the sample must be diluted using ultrapure water to produce the necessary analytical volume. Samples containing sulfide are normally diluted with deoxygenated water; however a small percentage of oxygen still remains dissolved in water even after deoxygenation with high-purity gas. For example, a $100-\mu \mathrm{L}$ sample diluted to a total volume of $10 \mathrm{~mL}$ has been diluted 100-fold. Moreover, sulfide can be oxidized by oxygen dissolved in the water used for dilution, possibly causing underestimation of results. Few reports of measuring hydrogen sulfide by spectrophotometry in microsamples exist because of the lack of adequate sampling tools and problems associated with dilution.

The purpose of this study was to determine the hydrogen sulfide content in a microsample using the methylene blue spectrophotometric method. We modified and used the original method developed by Cline, ${ }^{5}$ by taking full advantage of the features of the methylene blue. Dilution was carried out after coloring to avoid oxidation of sulfide by oxygen dissolved in the diluting solution. For ease of repeatability in other laboratories, all operations used a micropipette to measure volumes of hydrogen sulfide solution. This method was then applied to an investigation into the cause of death of Corbicula japonica 

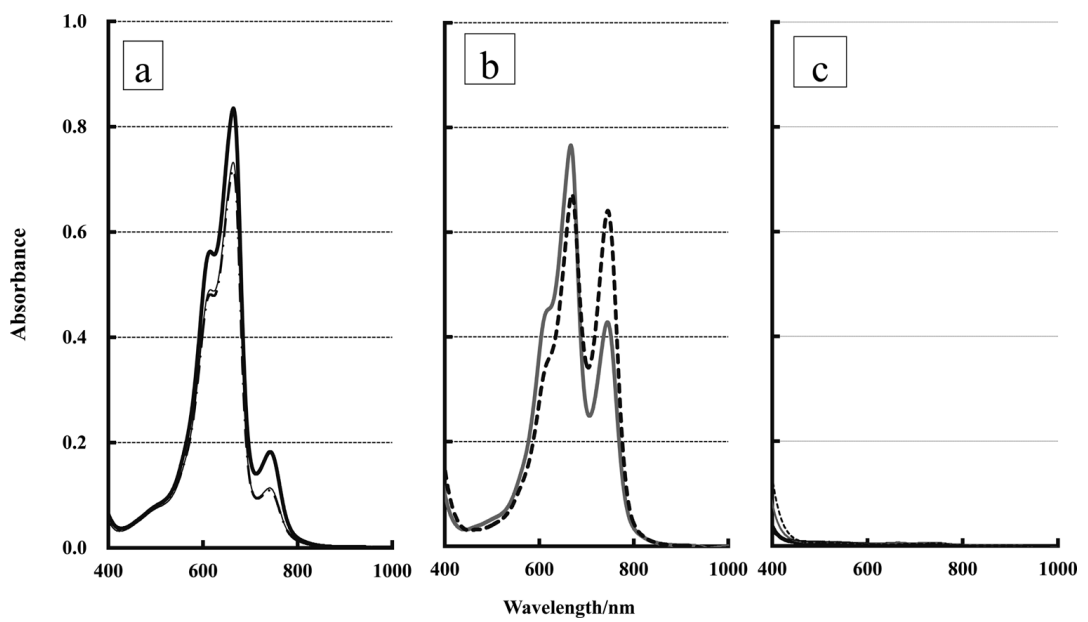

Fig. 1 Influence of $\mathrm{HCl}$ concentration on peak height. (a) Concentration of sulfide was $50 \mathrm{mgS} \mathrm{L}^{-1}$, the three lines are for ion-exchanged water (broken line), $0.01 \mathrm{M} \mathrm{HCl}$ (solid line) and $0.1 \mathrm{M} \mathrm{HCl}$ (heavy line), respectively. (b) Concentration of sulfide was $50 \mathrm{mgS} \mathrm{L}^{-1}$, the two lines are for $0.5 \mathrm{M}$ (gray line) and $1.0 \mathrm{M} \mathrm{HCl}$ (thick broken line), respectively. (c) Concentration of sulfide was $0 \mathrm{mgS} \mathrm{L}^{-1}$, the five lines are the same as (a) and (b).

in Lake Shinji (a brackish lake in Shimane, Japan), where we focused on sulfide generated by sulfate-reducing bacteria inside their shells.

\section{Experimental}

\section{Reagents and chemicals}

A $100 \mathrm{mgS} \mathrm{L}^{-1}$ standard sulfide solution was prepared by dissolving sodium sulfide $\left(\mathrm{Na}_{2} \mathrm{~S} \cdot 9 \mathrm{H}_{2} \mathrm{O}, 1.0 \mathrm{~g}\right.$; Wako Pure Chemicals, analytical grade) in deoxygenated water $(100 \mathrm{~mL})$. The prepared solution was standardized iodometrically.

A sulfide coloring reagent was prepared by dissolving $N, N$-dimethyl- $p$-phenylenediamine sulfate $(0.4 \mathrm{~g}$; SigmaAldrich, technical grade) and iron(III) chloride $\left(\mathrm{FeCl}_{3} \cdot 6 \mathrm{H}_{2} \mathrm{O}\right.$, $0.6 \mathrm{~g}$; Wako Pure Chemicals, analytical grade) in $6 \mathrm{M} \mathrm{HCl}$ (100 mL; Wako Pure Chemicals, analytical grade).

Deoxygenated water was prepared by thorough treatment with $\mathrm{N}_{2}$ gas $(>99.99 \%)$ to remove dissolved oxygen. A Shimadzu UV-1600 spectrophotometer with a 10-mm semi-micro glass cell (GL Sciences, $4 \mathrm{~mm}$ inside width) was used to determine sulfide concentration.

\section{Standard procedure}

The sample $(200 \mu \mathrm{L})$ was added to a test tube (IWAKI: $15 \times 105 \mathrm{~mm})$ containing the mixed coloring reagent $(200 \mu \mathrm{L})$ using a micro-pipette (Nichiryo, 00-NLE-200). When adding the sample, the tip of the micropipette was placed at the bottom of the test tube, and the sample was added slowly. The mixture was left to stand for $15 \mathrm{~min}$ without further mixing. Then $5 \mathrm{~mL}$ of $0.1 \mathrm{M} \mathrm{HCl}$ was added and absorbance was spectrophotometrically measured at $667 \mathrm{~nm}$ within $2 \mathrm{~h}$, inside a 10-mm semi-micro cell.

\section{Results and Discussion}

\section{Selection of cell for spectrophotometric measurements}

A 10-mm cell was used for the determination of hydrogen sulfide using the modified methylene blue method. Assuming the sample volume was $200 \mu \mathrm{L}$ and the solution volume required for the measurement (including rinsing the cell with water) was $10 \mathrm{~mL}$; the $200 \mu \mathrm{L}$ sample was diluted 50-fold. As previously mentioned, high dilution rates can lead to results that are below the detection limits. Therefore, it is better to use lower dilution rates. Thus, in this study, a 10-mm semi-micro cell (with $4 \mathrm{~mm}$ internal width) was used, which required only a $5-\mathrm{mL}$ volume for rinsing the cell and for subsequent analysis.

\section{Dilution method}

When subjected to small changes in $\mathrm{pH}$, the methylene blue does not decompose. ${ }^{5}$ In the previous study, the sample solution was diluted using water and the absorbances were measured over four concentration ranges of hydrogen sulfide $(0-3$, $3-40,40-250$, and $250-1000 \mathrm{~g} \mathrm{~L}^{-1}$ ) by changing the rate of dilution. $^{5}$ In the molybdenum blue method,$^{10}$ indophenol blue method, ${ }^{11}$ and diazotization method, ${ }^{12}$ used for the determination of nutrients such as phosphate, phosphorus, and nitrogen, small $\mathrm{pH}$ changes cause the methylene blue to decompose. Our study takes full advantage of the $\mathrm{pH}$ resistance of methylene blue, by diluting the sample after coloring to prevent sulfide oxidation by oxygen dissolved in the dilution water.

\section{Ensuring amounts of solution for measurement}

As previously mentioned, we have to operate in an open system when measuring hydrogen sulfide samples at the microscale, because no specialized tools are available. When samples were added to the mixed coloring reagent in the open system, three competing reactions were possible: (i) sulfide oxidization by air, (ii) sulfide volatilization into the air, and (iii) complexation with methylene blue. Hydrogen sulfide would be oxidized and volatilized before formation of methylene blue if the sample was added above the mixed coloring reagent and mixed in the test tube. Therefore, in this study, we utilized an elongated test tube, in which $200 \mu \mathrm{L}$ mixed coloring reagent was $4 \mathrm{~mm}$ deep. The sample was collected by micropipette and the tip of the micropipette was placed at the bottom of the test tube, under the surface of the mixed coloring reagent. The sample was then added slowly, and the system was allowed to stand for 15 min without mixing. Next, the optimum solution to 
Table 1 Influence of $\mathrm{HCl}$ concentration on quantitative range and coefficient of determination

\begin{tabular}{lccccc}
\hline \multirow{2}{*}{ Item } & \multicolumn{5}{c}{$\mathrm{HCl}$ concentration/mol L-1 } \\
\cline { 2 - 6 } & 0.0 & 0.01 & 0.1 & 0.5 & 1.0 \\
\cline { 3 - 7 } $\begin{array}{c}\text { Quantitative range/ } \\
\text { mgS L }\end{array}$ & $0.2-30$ & $0.2-30$ & $0.1-50$ & $0.2-50$ & $0.2-30$ \\
$\begin{array}{c}\text { Coefficient of } \\
\text { determination }\left(R^{2}\right)\end{array}$ & 0.990 & 0.995 & 0.993 & 0.991 & 0.997 \\
\hline
\end{tabular}

be used for dilution was investigated. $\mathrm{HCl}$ was used because it was already present in the mixed coloring reagent. The effect of $\mathrm{HCl}$ concentration on the absorbance was examined. A hydrogen sulfide standard solution ( 0 or $50 \mathrm{mgS} \mathrm{L}^{-1}$ ) was added to test tubes containing $200 \mu \mathrm{L}$ of mixed coloring reagent, followed by $5 \mathrm{~mL}$ of ion-exchanged water, $0.01,0.1,0.5$ or $1.0 \mathrm{M} \mathrm{HCl}$. When $0.1 \mathrm{M} \mathrm{HCl}$ was used as a diluting solution, the peak height at $667 \mathrm{~nm}$ was higher than that observed for any other solution (Figs. 1a and 1b). In the range of $0.1-1.0 \mathrm{M} \mathrm{HCl}$, the peak height at $667 \mathrm{~nm}$ decreased with increasing $\mathrm{HCl}$ concentration, while the peak height at $740 \mathrm{~nm}$ increased. It therefore appears that the absorption band of methylene blue occurs at $740 \mathrm{~nm}$ instead of $667 \mathrm{~nm} .^{5}$ In the blank test $\left(0 \mathrm{mgS} \mathrm{L}{ }^{-1}\right)$, ion-exchanged water and four $\mathrm{HCl}$ solutions had no effect on the absorption spectrum (Fig. 1c).

\section{Calibration curve}

Next, we established the quantitative range using $0-100$ $\mathrm{mgS} \mathrm{L}{ }^{-1}$ hydrogen sulfide standard solutions. The results showed that sulfide could be determined using all the solutions and that all the coefficients of determination $\left(R^{2}\right)$ were over 0.99 (Table 1). However, the widest quantitative range (0.1$50 \mathrm{mgS} \mathrm{L}^{-1}$ ) was found for $0.1 \mathrm{M} \mathrm{HCl}$. Moreover, results obtained using $0.1 \mathrm{M} \mathrm{HCl}$ as the diluting solution showed good linearity (average of $R^{2}(n=4)$ was $0.998 \pm 0.4$, RSD $=0.1 \%$ ) and good reproducibility (average of slope $(n=4)$ was $54.5 \pm 0.4, \mathrm{RSD}=0.67 \%$ ).

The influence of mixing after adding the sample was tested. First, $200 \mu \mathrm{L}$ of sulfide standard solution $\left(10\right.$ or $\left.50 \mathrm{mgS} \mathrm{L}^{-1}\right)$ was added to a test tube containing $200 \mu \mathrm{L}$ mixed coloring reagent by using a micropipette. Next, the solution in the test tube was shaken 2 or 3 times and sulfide was measured according to the standard procedure. The mean values of the results $(n=4)$ were $7.0 \pm 4.2$ (average \pm SD) and $23.7 \pm 15.6$ $\mathrm{mgS} \mathrm{L}{ }^{-1}$; and RSD values were 59 and $66 \%$, respectively. When mixed coloring reagent was added to the 10 or $50 \mathrm{mgS} \mathrm{L}^{-1}$ of sulfide, the results were $7.2 \pm 1.3$ and $26.5 \pm 5.3 \mathrm{mgS} \mathrm{L}^{-1}$; and RSD were 18 and $20 \%$, respectively. It seemed that the decrease of sulfide concentration was oxidized by air and then volatilized. As a result, we modified the method so that the sample was added carefully to a test tube containing pre-mixed coloring reagent and the setup was allowed to stand for 15 min without mixing.

\section{Application to Corbicula japonica shells}

Recently, deaths of $C$. japonica occurred in Lake Shinji during the summer season. In order to investigate the cause of death, the newly developed method was used to measure sulfide content in the shells of $C$. japonica. Three $C$. japonica shells were put in a $100-\mathrm{mL}$ glass syringe and $80 \mathrm{~mL}$ of deoxygenated seawater (at a salinity of 5 ; and $\mathrm{pH} 8$ ) were added. Ten syringes were prepared by placing them into a water bath at $25^{\circ} \mathrm{C}$ and incubating them under dark conditions. Every $24 \mathrm{~h}$, one syringe was removed and was used to measure sulfide in both the shell and the rearing water. The inner shell water was collected when the shell was slightly opened using a scalpel and a plastic wedge driven between the upper and lower shells. Sulfide was measured in the solution that dripped from the shell. The inner shell water volume was up to $250 \mu \mathrm{L}$, and $200 \mu \mathrm{L}$ of the sample was collected by micropipette and measured. Rearing water was filtered (to $0.45 \mu \mathrm{m}$ ) from a $100-\mathrm{mL}$ glass syringe to a 20-mL syringe via a three-way trap, and sulfide in the filtered water was measured. In addition, every $24 \mathrm{~h}$, fresh rearing water was used. Sulfide was not detected in either the shell or the rearing water immediately after the start of the experiment. After $24 \mathrm{~h}, 1.5 \mathrm{mgS} \mathrm{L}^{-1}$ of sulfide was detected in the shell, but sulfide was still not detected in the rearing water. However, after $48 \mathrm{~h}$, an average of $3.5 \mathrm{mgS} \mathrm{L}^{-1}$ sulfide was detected in the shell.

These results revealed that sulfide was generated in the shells of $C$. japonica under hypoxic conditions, since $C$. japonica exposed to sulfide directly would have shorter lifetimes. It is therefore necessary to investigate the influence of sulfide on C. japonica in further detail.

The tools used in this study, such as test tubes and pipettes, are affordable and readily available. Moreover, all operations used pipettes, which anyone can operate and use to measure sulfide concentrations. For microliter sized sample volumes (e.g. $200 \mu \mathrm{L}$ ), it was possible to measure sulfide by collection with a micropipette. Previously, these sample volumes were too small to allow measurement of sulfide; however, with our method, sulfide can easily be measured in microsamples such as inner shell water samples. Therefore, this method can be applied to a variety of fields of study.

\section{Acknowledgements}

Funding was provided by the River Technology Research and Development System, Regional Issues Field (River Ecosystems) and by consignment study from Shimane Prefecture.

\section{References}

1. R. J. Diaz and R. Rosenberg, Oceanogr. Mar. Biol., 1995, 33, 245.

2. R. Vaquer-Sunyer and C. M. Duarte, Limnol. Oceanogr., 2010, 55, 1075.

3. B. Vismann, Ophelia, 1991, 34, 1.

4. B. Vismann, J. Exp. Mar. Biol. Ecol., 1996, 204, 141.

5. J. D. Cline, Limnol. Oceanogr., 1996, 14, 454.

6. S. Sugahara, T. Yurimoto, K. Ayukawa, K. Kimoto, Y. Senga, M. Okumura, and Y. Seike, Bunseki Kagaku, 2010, $59,1155$.

7. W. Davison and J. P. Lishman, Analyst, 1983, 108, 1235.

8. S. Sugahara, T. Yurimoto, K. Ayukawa, K. Kimoto, Y. Senga, M. Okumura, and Y. Seike, Jpn. J. Limnol., 2012, 73, 23.

9. S. Sugahara, H. Kamiya, Y. Suyama, Y. Senga, K. Ayukawa, M. Okumura, and Y. Seike, Landscape Ecol. Eng., 2015, $11,269$.

10. J. Murphy and J. P. Riley, Anal. Chim. Acta, 1962, 27, 31.

11. T. Sagi, Oceanogr. Mag., 1966, 18, 43.

12. K. Bendschneider and R. J. Robinson, J. Mar. Res., 1952, 11,87 . 